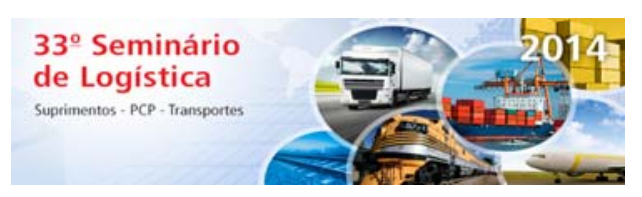

Tema: Movimentação e Armazenagem

\title{
AUTOMATIZAÇÃO DAS OPERAÇÕES DOS ALMOXARIFADOS ATRAVÉS DA IMPLANTAÇÃO SAP CONSOLE E UTILIZAÇÃO DO SAP/WM - WAREHOUSE MANAGEMENT NA ARCELORMITTAL TUBARÃO*
}

\section{Resumo}

Ricardo Rodrigues Grizotti ${ }^{1}$ Pablo Silva da Rocha ${ }^{2}$ Leonardo Saleme Gomes ${ }^{3}$

\begin{abstract}
O trabalho tem por objetivo demonstrar o processo de implantação da ferramenta SAP Console (Rádio Frequência-RF) com utilização do Módulo de WM - Warehouse Management do SAP para a automatização das operações dos almoxarifados, visando agilizar com precisão o fluxo de informações, melhorando a operacionalidade do recebimento, estocagem, separação, distribuição, inventário, inspeção e preservação de materiais, promovendo a otimização dos processos e do espaço físico, pelo gerenciamento eficiente de informação e recursos, permitindo tirar o máximo proveito dessas atividades adotando diferenciais com a melhor aderência aos processos da ArcelorMittal Tubarão.
\end{abstract}

Palavras-chave: Armazenagem; Automatização; SAP Console WMS; Warehouse Management System.

\section{AUTOMATION OF OPERATIONS FOR WAREHOUSES BY DEPLOYING SAP CONSOLE AND USING THE SAP I WM - WAREHOUSE MANAGEMENT AT ARCELORMITTAL TUBARÃO}

\begin{abstract}
The work has for objective to demonstrate the process of implementing the SAP Console tool (Radio-Frequency RF) with use of the module WM - Warehouse Management SAP to automate the operations of warehouses, accurately in order to speed the flow of information, improving operability of the receipt, storage, separation, distribution, inventory, inspection and preservation of materials, promoting the optimization of processes and the physical space, the efficient management of information and resources, allowing you to take full advantage of these activities by adopting differential with improved adherence to processes of ArcelorMittal Tubarão.

Keywords: Storage; Automation; SAP Console; WMS; Warehouse Management System.

1 Administrador, Analista de Processos de Suprimentos, ArcelorMittal Tubarão, Serra, ES, Brasil.

2 Sistema de Informação, Analista de Processos de Suprimentos, ArcelorMittal Tubarão, Serra, ES, Brasil.

3 Administração Gestão Empresarial, Analista de Processos de Suprimentos, ArcelorMittal Tubarão, Serra, ES, Brasil.
\end{abstract}

\footnotetext{
* Contribuição técnica ao $33^{\circ}$ Seminário de Logística - Suprimentos, PCP, Transportes, 13 a 16 de maio de 2014, São Paulo, SP, Brasil. 


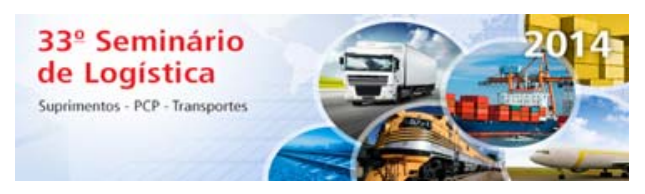

\section{INTRODUÇÃo}

Ao longo dos 30 anos de Operação da ArcelorMittal Tubarão os Almoxarifados tem como missão manter o estoque de materiais destinados a abastecer as diversas áreas existentes em nossa unidade operacional, fornecendo bens adequados às diferentes necessidades de cada departamento.

Visando buscar a excelência no gerenciamento e controle dos materiais armazenados no Almoxarifado, o Projeto de Automatização dos Almoxarifados tem como objetivo tornar suas operações mais ágeis e eficientes, buscando otimizar o processamento das informações com mais rapidez, redução do tempo de permanência das mercadorias nas áreas de transferência e gerando maior rastreabilidade dos processamentos. A ideia é de se criar um ambiente mais dinâmico e agradável de trabalho gerando um padrão de gestão e controle para todos os envolvidos no processo.

Mantendo a estratégia de buscar novos aprendizados, mas, no entanto, preservando suas melhores práticas e valores configurados nos processos existentes, em todo período da fase "Análise e Revisão de Processo", foram esgotadas as visões de melhor aderência entre ferramentas e processos, para buscar soluções dentro do ciclo da Cadeia de Suprimentos.

Em razão da forte iniciativa em não perder valores e sim agregar soluções, foi decidido envidar esforços junto a Consultoria para atender as especificações alcançadas no projeto, particularmente em especial a ferramenta SAP Console ligado ao Módulo WM Warehouse Management.

\section{CONSIDERAÇÕES}

De acordo com Banzato [1], um WMS é um sistema de gestão de armazéns, que otimiza todas as atividades operacionais (fluxo de materiais) e administrativas (fluxo de informações) dentro do processo de armazenagem, incluindo recebimento, inspeção, endereçamento, estocagem, separação, embalagem, carregamento, expedição, emissão de documentos, inventário, entre outras, que integradas atendem às necessidades logísticas, maximizando os recursos e minimizando desperdícios de tempo e de pessoas.

Adotar o módulo de WM como um recurso para administrar e rastrear todos os processos de movimentação de mercadorias interligada a ferramenta SAP Console; recebimento, armazenagem, separação, expedição, minimizando gargalos no gerenciamento de alocação de recursos humanos, equipamentos mecânicos e endereços, com o menor custo possível, eliminando o desperdício sem perder a capacidade de reação estejam inseridos num processo sistêmico atendendo aos Padrões Empresariais da ArcelorMittal Tubarão.

Uma das vantagens do WM é a capacidade de administrar as quantidades em estoque em cada posição individual no almoxarifado em instalações de armazenamento altamente complexas. Isso significa que, com o Sistema de Administração de Depósito (WM), é possível otimizar a utilização das posições no almoxarifado, misturar materiais pertencentes a diversas áreas distribuídos aleatoriamente nos almoxarifados-posições e saber exatamente, todo o tempo, onde um determinado material está localizado.

\footnotetext{
* Contribuição técnica ao $33^{\circ}$ Seminário de Logística - Suprimentos, PCP, Transportes, 13 a 16 de maio de 2014, São Paulo, SP, Brasil. 


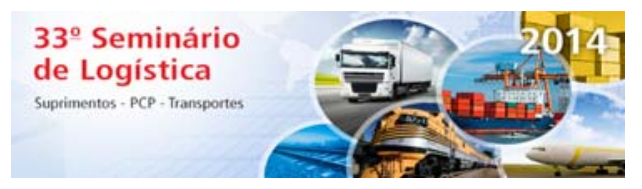

Visando buscar uma ferramenta que potencialize o WM a solução SAP Console permite criar transações SAP (Módulo WM) diretamente em equipamentos de Rádio Frequência (RF), sejam terminais portáteis ou fixos montados nos empilhadores. Integrada no "Logistics Execution System (LES)" do que faz parte do licenciamento SAP ECC 6.0.

Este conceito de ter em terminais móveis e em tempo real, as transações e toda a lógica de negócio presente no sistema central SAP, permite aumentar significativamente a produtividade, obtendo níveis de confiabilidade muito elevados e uma rastreabilidade completa de todas as operações. Esta solução reduz drasticamente a utilização de papel nas operações de manuseamento de materiais nos almoxarifados ou nos processos produtivos.

A simplicidade e rapidez de implementação, assim como de customização, fazem com que esta solução apresente um excelente custo/benefício e um rápido retorno do investimento.

É possível potenciar todas as funcionalidades do SAP Console a qualquer processo logístico do SAP ECC 6.0 mesmo que não envolvam o módulo de Gestão de Armazéns (WM), tais como Gestão de Materiais, Gestão da Manutenção, Gestão de Serviços Técnicos ou Planeamento e Controlo de Produção e o Módulo QM (Quality Management), o qual também inserimos no contexto do projeto, e desta forma inferindo maior rapidez e confiabilidade a todas as operações, utilizando qualquer tipo de terminal com capacidades de leitura de códigos de barras.

Objetivamente deve-se aprimorar com o tempo o uso do recurso SAP Console com os Módulos WM e QM aproveitando melhor suas potencialidades como ferramenta integrada no fluxo do processo e na visão de gerenciamento.

\section{IMPLEMENTAÇÃO DA INICIATIVA}

\subsection{Premissas}

Considerando ser de fundamental importância a sistematização do processo, definimos por nos orientar pelos seguintes princípios:

- Potencializar as Condições do SAP Console e Módulo SAP/WM;

- Garantir que o Processo tenha Controle Sistêmico;

- Gerar Inteligência Sistêmica visando Otimizar o Fluxo Estocagem;

- Obter Flexibilidade de Rastreabilidade;

- Criar Cenários de Gerenciamento em BW (Business Warehouse).

\subsection{Organização}

Para organizar e facilitar o desenvolvimento da prática, de forma regulamentada, garantindo que os preceitos básicos, sejam atendidos, com metodologia para obter a consecução dos resultados esperados, definiu-se por tratar o seguinte processo de movimentação de materiais:

- Armazenagem.

\footnotetext{
* Contribuição técnica ao $33^{\circ}$ Seminário de Logística - Suprimentos, PCP, Transportes, 13 a 16 de maio de 2014, São Paulo, SP, Brasil. 


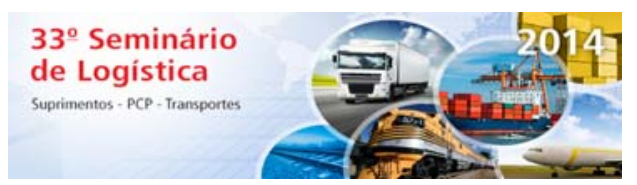

No sentido de proporcionar uma visão geral do WMS e suas principais funções para o SAP Console sugerindo sua adaptação as regras de negócio garantindo o nível de Parametrização e Customização devendo configurar plenamente as regras de negócio e assegurar a mobilidade necessária para permitir desenvolvimentos futuros. A metodologia utilizada foi baseada na tabela abaixo que demonstra as funções do WMS tradicional utilizada na armazenagem e as sugestões de adaptação para as regras de negócio da AMT a ser tratada:

Tabela 1. Tabela das Principais funções WMS

\begin{tabular}{|c|c|c|}
\hline $\begin{array}{l}\text { Funções do } \\
\text { WMS }\end{array}$ & Armazenagem & $\begin{array}{l}\text { Sugestões para as Regras } \\
\text { de Negócio }\end{array}$ \\
\hline Recebimento & $\begin{array}{l}\text { Identifica e seleciona o } \\
\text { recebimento a ser processado, } \\
\text { indica os itens e qtd a serem } \\
\text { recebidos, imprime e identifica o } \\
\text { material, confirma o recebimento } \\
\text { da quantidade de cada produto e } \\
\text { libera os itens para a estocagem. }\end{array}$ & $\begin{array}{l}\text { Identificar e selecionar o } \\
\text { recebimento de material } \\
\text { imprimindo o documento de } \\
\text { entrada direcionando a local } \\
\text { de entrega dos materiais para } \\
\text { a inspeção e estocagem. } \\
\text { (MM-WM-QM) }\end{array}$ \\
\hline $\begin{array}{l}\text { Inspeção e } \\
\text { controle de } \\
\text { qualidade }\end{array}$ & $\begin{array}{l}\text { Notifica o operador de inspeção } \\
\text { das necessidades dos materiais } \\
\text { recebidos, permitindo a entrega } \\
\text { imediata de produtos à inspeção } \\
\text { ou à notificação imediata para que } \\
\text { um inspetor venha à recepção; } \\
\text { confirma e libera a inspeção } \\
\text { quando os produtos ficam } \\
\text { estocados em quarentena, } \\
\text { evitando a separação física do } \\
\text { material. }\end{array}$ & $\begin{array}{l}\text { Identificar os produtos com } \\
\text { defeitos, problemas de } \\
\text { validade, avarias em geral, nas } \\
\text { mercadorias recebidas, } \\
\text { notificar imediatamente as } \\
\text { irregularidades e as } \\
\text { encaminhar para o estoque } \\
\text { provisório para posterior } \\
\text { devolução ao fornecedor. (QM- } \\
\text { WM) }\end{array}$ \\
\hline Estocagem & $\begin{array}{l}\text { Analisa o melhor método de } \\
\text { estocagem, considerando local, } \\
\text { tipo de equipamento, momento } \\
\text { oportuno para estocar; possibilita o } \\
\text { conhecimento do que está } \\
\text { estocado; apóia o recebimento do } \\
\text { material que entra; a consolidação } \\
\text { de números de mesmo item; } \\
\text { inventário rotativo e zoneamento } \\
\text { de áreas de produtos. }\end{array}$ & $\begin{array}{l}\text { Analisar o melhor método de } \\
\text { estocagem de acordo com o } \\
\text { mapa de estocagem definido } \\
\text { pela criticidade de estocagem. } \\
\text { (MM-WM) }\end{array}$ \\
\hline Transferências & $\begin{array}{l}\text { Gerencia os fluxos de transferência } \\
\text { de itens entre áreas, ou de um } \\
\text { depósito para outro, seja próprio } \\
\text { ou terceirizado. }\end{array}$ & $\begin{array}{l}\text { Gerencia os fluxos de } \\
\text { transferência dos materiais } \\
\text { entre os almoxarifados. (WM) }\end{array}$ \\
\hline
\end{tabular}

* Contribuição técnica ao $33^{\circ}$ Seminário de Logística - Suprimentos, PCP. Transportes, 13 a 16 de maio de 2014, São Paulo, SP, Brasil. 


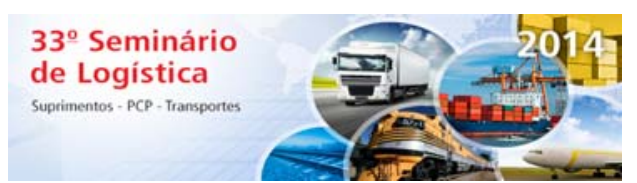

\begin{tabular}{|c|c|c|}
\hline $\begin{array}{l}\text { Separação de } \\
\text { pedidos }\end{array}$ & $\begin{array}{l}\text { Transmite os pedidos de mais alta } \\
\text { prioridade aos separadores de } \\
\text { pedidos; se as prioridades forem } \\
\text { iguais, transmite as solicitações de } \\
\text { separação com base nos critérios } \\
\text { pré-definidos. }\end{array}$ & $\begin{array}{l}\text { Gera via processamento lista } \\
\text { de picking dos materiais para } \\
\text { separação incluindo os } \\
\text { endereçamentos para a } \\
\text { expedição. (WM) }\end{array}$ \\
\hline Expedição & $\begin{array}{l}\text { Inclui a roteirização dos produtos } \\
\text { separados para as devidas áreas } \\
\text { de separação de cargas na } \\
\text { expedição; a geração automática } \\
\text { dos conhecimentos de embarque e } \\
\text { atualização automática de arquivos } \\
\text { de pedidos abertos de clientes. }\end{array}$ & $\begin{array}{l}\text { Inclui a roteirização dos } \\
\text { materiais separados para as } \\
\text { devidas áreas de separação } \\
\text { de cargas na expedição; a } \\
\text { geração via processamento } \\
\text { dos conhecimentos de } \\
\text { embarque e atualização } \\
\text { automática de arquivos de } \\
\text { pedidos abertos dos usuários. } \\
\text { Realização do processamento } \\
\text { de entrega na modalidade Off } \\
\text { Line. (WM) }\end{array}$ \\
\hline Inventários & $\begin{array}{l}\text { Permite realizar os inventários } \\
\text { físicos de forma rápida e precisa, } \\
\text { executando-o por tipo de produtos } \\
\text { ou localizações físicas, também } \\
\text { podem ser feitas auditorias } \\
\text { internas sem bloqueio de } \\
\text { movimentação e de acordo com os } \\
\text { critérios da empresa, além de } \\
\text { acertos de inventários, tais como: } \\
\text { quebra; mudança de status de } \\
\text { produtos, etc. }\end{array}$ & $\begin{array}{l}\text { Permitir a realização dos } \\
\text { inventários físicos de forma } \\
\text { rápida e precisa dos materiais } \\
\text { estocados nas posições. (WM) }\end{array}$ \\
\hline Preservação & $\begin{array}{l}\text { Notifica o operador da preservação } \\
\text { em função do período de controle } \\
\text { dos materiais; confirma e libera a } \\
\text { preservação dos materiais } \\
\text { estocados e atualiza a próxima } \\
\text { data de controle. }\end{array}$ & $\begin{array}{l}\text { Identificar os materiais com } \\
\text { defeitos, problemas, avarias } \\
\text { em geral, notificar } \\
\text { imediatamente as } \\
\text { irregularidades e as } \\
\text { encaminhar para o estoque } \\
\text { provisório para posterior } \\
\text { alienação. (QM-WM) } \\
\end{array}$ \\
\hline Relatórios & $\begin{array}{l}\text { Fornece relatórios de desempenho } \\
\text { e informações operacionais que } \\
\text { subsidiam o processo de } \\
\text { gerenciamento do armazém. }\end{array}$ & $\begin{array}{l}\text { Fornece relatórios de } \\
\text { desempenho e informações } \\
\text { operacionais que subsidiam o } \\
\text { processo de gerenciamento do } \\
\text { almoxarifado. (WM) }\end{array}$ \\
\hline
\end{tabular}

Fonte: Adaptado de Banzato [1].

\subsection{Objetivo}

Implementar a solução para aplicar recurso de Mobilidade, com Tecnologia de Códigos de Barras disponíveis no mercado e integrado com funções da plataforma ERP SAP -

* Contribuição técnica ao $33^{\circ}$ Seminário de Logística - Suprimentos, PCP, Transportes, 13 a 16 de maio de 2014, São Paulo, SP, Brasil. 


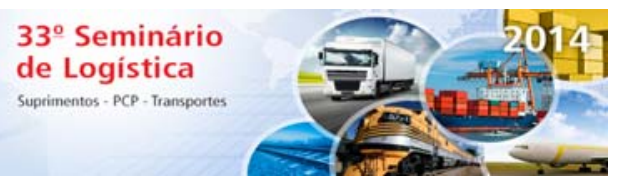

WM (Warehouse Management) em uso na ArcelorMittal Tubarão nos processos de Movimentações e Controles dos Almoxarifados da Área de Suprimentos.

\subsection{Benefícios e Expectativas Esperados}

De forma geral o benefício esperado é o de maximizar os recursos da solução de Mobilidade SAP Console com o que o Módulo de WM oferece de apoio a tarefas de armazenagem (Figura 1).

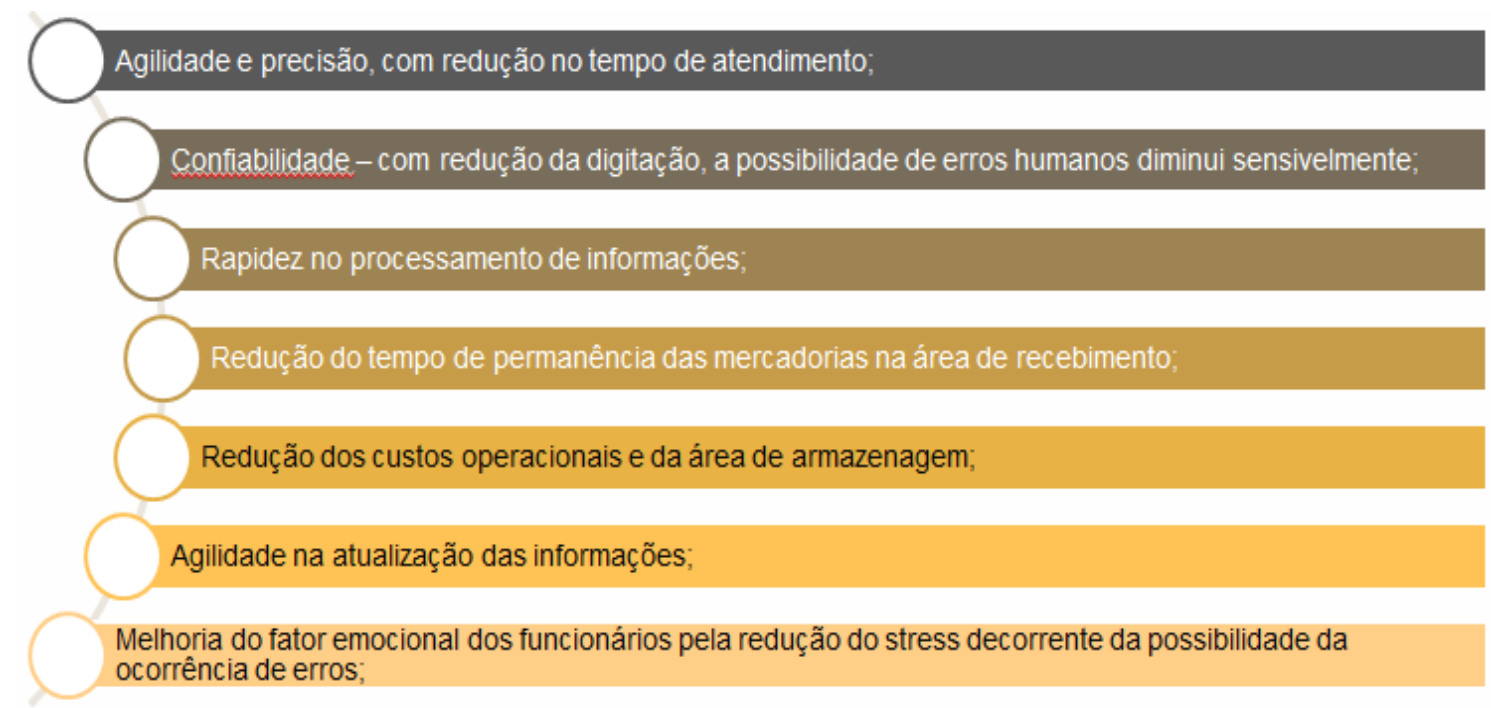

Figura 1. Benefícios e expectativas do projeto de automatização dos almoxarifados [2].

\section{O PROCESSO DE IMPLANTAÇÃO}

\subsection{Macro Plano}

Inicialmente, para estabelecer uma orientação de planejamento para as atividades da implantação as parametrizações foram definidas para atingir diversos objetivos. Esses objetivos definem os parâmetros para o tipo e âmbito dos resultados de controle previstos. Tais objetivos incluem:

- definir a criticidade das áreas de armazenagens e posições, baixa, média e alta rotatividade;

- definir a regra de estocagem para materiais, entrada e saídas dos almoxarifados;

- reduzir o tempo de separação dos materiais;

- melhorar a performance e resultado do inventário;

- melhorar a assertividade/rastreabilidade do processo de entrega de materiais.

Para atingir os itens descritos acima, inicialmente realizamos um estudo do trade-off de custos: Espaço x Movimentação. Diante das características dos materiais e as condições atuais da estocagem verticalizada ficou evidente o tipo de armazenagem aleatória (itens são estocados em posições aleatórias, resultando em menores custos

* Contribuição técnica ao $33^{\circ}$ Seminário de Logística - Suprimentos, PCP, Transportes, 13 a 16 de maio de 2014, São Paulo, SP, Brasil. 


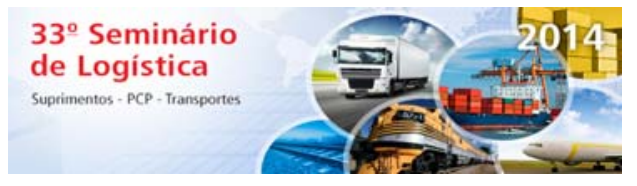

de espaços (pela compactação) e maiores custos de movimentação), desta forma foi aplicado o modelo de cálculo de distancia e atividade por criticidade conforme Figura 2.

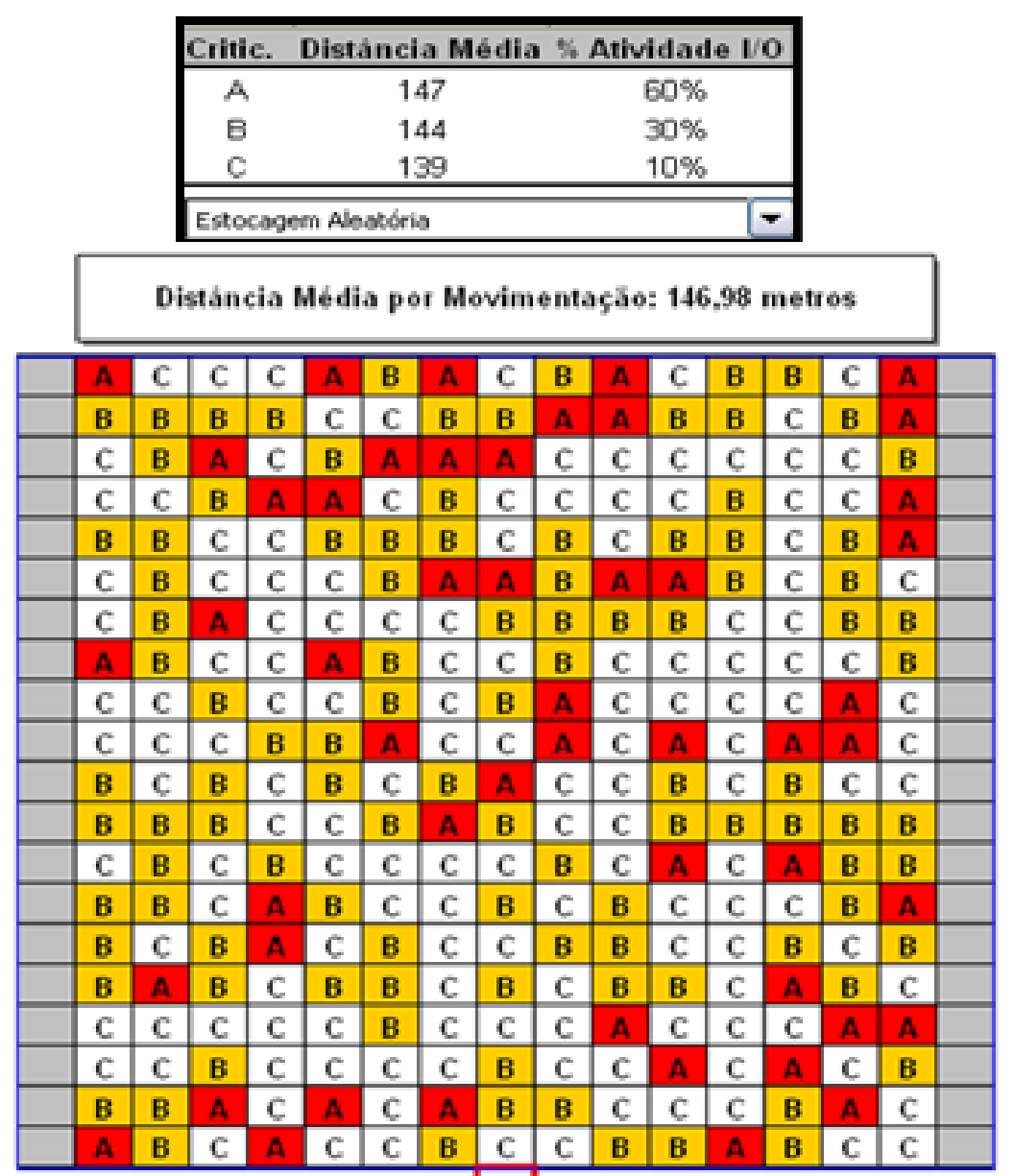

Legenda: Criticidade: $A$ - Estocagem de Materiais de Alta Rotatividade; Criticidade: $B$ - Estocagem de Materiais de Média Rotatividade; Criticidade: C - Estocagem de Materiais de Baixa Rotatividade.

Figura 2. Matriz de cálculo de distancia e atividade por criticidade de estocagem aleatória [3].

Diante do resultado que foi apresentado aplicou-se a mesma metodologia para a possibilidade de mudança do modelo de estocagem para dedicada (itens são estocados em posições pré-definidas, resultando em maiores custos de espaço e menores custos de movimentação (itens de maior transito são alocados próximos às entradas e saídas)), conforme modelo da Figura 3.

* Contribuição técnica ao $33^{\circ}$ Seminário de Logística - Suprimentos, PCP, Transportes, 13 a 16 de maio de 2014, São Paulo, SP, Brasil. 


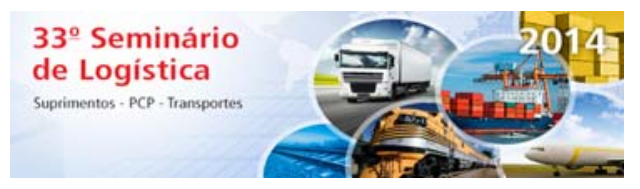

\begin{tabular}{|c|c|c|c|}
\hline \multirow{2}{*}{$\frac{\text { Critic. }}{\mathrm{A}}$} & \multicolumn{3}{|c|}{ Distáncia Média \% Atividade I/O } \\
\hline & 51 & $60 \%$ & \\
\hline B & 120 & $30 \%$ & \\
\hline $\mathrm{C}$ & 207 & $10 \%$ & \\
\hline Estocas & jem Dedicada & & - \\
\hline
\end{tabular}

\begin{tabular}{|c|c|c|c|c|c|c|c|c|c|c|c|c|c|c|}
\hline \multicolumn{15}{|c|}{ Distáncia Média por Movimentaçăo: 94,74 metros } \\
\hline C & $\mathrm{C}$ & $\mathrm{C}$ & $\mathrm{C}$ & $\mathrm{C}$ & C & $\mathrm{C}$ & $\mathrm{C}$ & C & $\mathrm{C}$ & $\mathrm{C}$ & $\mathrm{C}$ & $\mathrm{C}$ & C & C \\
\hline C & $\mathrm{C}$ & $\mathrm{C}$ & $\mathrm{C}$ & $\mathrm{C}$ & c & $\mathrm{C}$ & C & $\mathrm{C}$ & $\mathrm{C}$ & C & C & $\mathrm{C}$ & C & C \\
\hline C & $\mathrm{C}$ & $\mathrm{C}$ & $\mathrm{C}$ & $\mathrm{C}$ & C & $\mathrm{C}$ & C & $\mathrm{C}$ & C & C & C & $\mathrm{C}$ & C & C \\
\hline C & C & C & C & C & C & $\mathrm{C}$ & C & $c$ & C & C & C & C & C & C \\
\hline C & $\mathrm{C}$ & C & C & $\mathrm{C}$ & C & $\mathrm{C}$ & C & C & C & C & C & $\mathrm{C}$ & C & C \\
\hline C & C & C & C & $\mathrm{C}$ & C & $\mathrm{C}$ & C & C & C & C & C & C & C & C \\
\hline C & C & C & C & $\mathrm{C}$ & C & $\mathrm{C}$ & C & $c$ & C & C & C & C & C & C \\
\hline C & $\mathrm{C}$ & $\mathrm{C}$ & $\mathrm{C}$ & $\mathrm{C}$ & C & $\mathrm{C}$ & C & C & C & C & C & $\mathrm{C}$ & C & C \\
\hline B & B & B & B & B & B & B & B & B & B & B & B & B & B & B \\
\hline B & B & B & B & B & B & B & B & B & B & B & B & B & B & B \\
\hline B & B & B & B & B & B & B & B & B & B & B & B & B & B & B \\
\hline B & B & B & B & B & B & B & B & B & B & B & B & B & B & B \\
\hline B & B & B & B & B & B & B & B & B & B & B & B & B & B & B \\
\hline B & B & B & A & A & A & A & A & A & A & A & A & B & B & B \\
\hline B & B & B & A & A & A & A & A & A & A & A & A & B & B & B \\
\hline B & B & B & A & A & A & A & A & A & A & A & A & B & B & B \\
\hline B & B & B & $A$ & $A$ & A & A & A & A & $A$ & $A$ & A & B & B & B \\
\hline B & B & B & A & A & A & A & A & A & A & A & A & B & B & B \\
\hline B & B & B & A & A & A & A & A & A & A & A & A & B & B & B \\
\hline B & B & B & A & A & A & A & A & A & A & A & A & B & B & B \\
\hline
\end{tabular}

Figura 3. Matriz de Cálculo de Distancia e Atividade por Criticidade de Estocagem Dedicada [3].

Desta forma ao comparar o modelo atual (estocagem aleatório) contra o modelo proposto (estocagem dedicada) fica evidenciado a possibilidade de agilizar o fluxo de informações dentro do almoxarifado, melhorando a operacionalidade da estocagem e promovendo a otimização do processo e do espaço, pelo gerenciamento eficiente de informação e recursos. Essa parte do trabalho compreende em estruturar atividades de forma que numa evolução contínua o almoxarifado será melhor organizado no quesito de localização dos materiais de forma a suas estratégias de entrada e saída sejam otimizadas, sempre pautado em intensidade de giro dos materiais.

Para atingir os itens descritos acima, utilizamos na estrutura do sistema de administração de depósitos, de acordo com a figura 4, à área de armazenamento para a alocação da criticidade das áreas de armazenagem/posição depósito. De acordo com a SAP - Knowledge Warehouse [4], uma área de armazenagem é uma área dentro de um tipo de depósito na qual todas as atividade de armazenagem são executadas do mesmo modo. A área de armazenagem agrupa posições no depósito do ponto de vista de estratégias de armazenagem.

\footnotetext{
* Contribuição técnica ao $33^{\circ}$ Seminário de Logística - Suprimentos, PCP. Transportes, 13 a 16 de maio de 2014, São Paulo, SP, Brasil. 

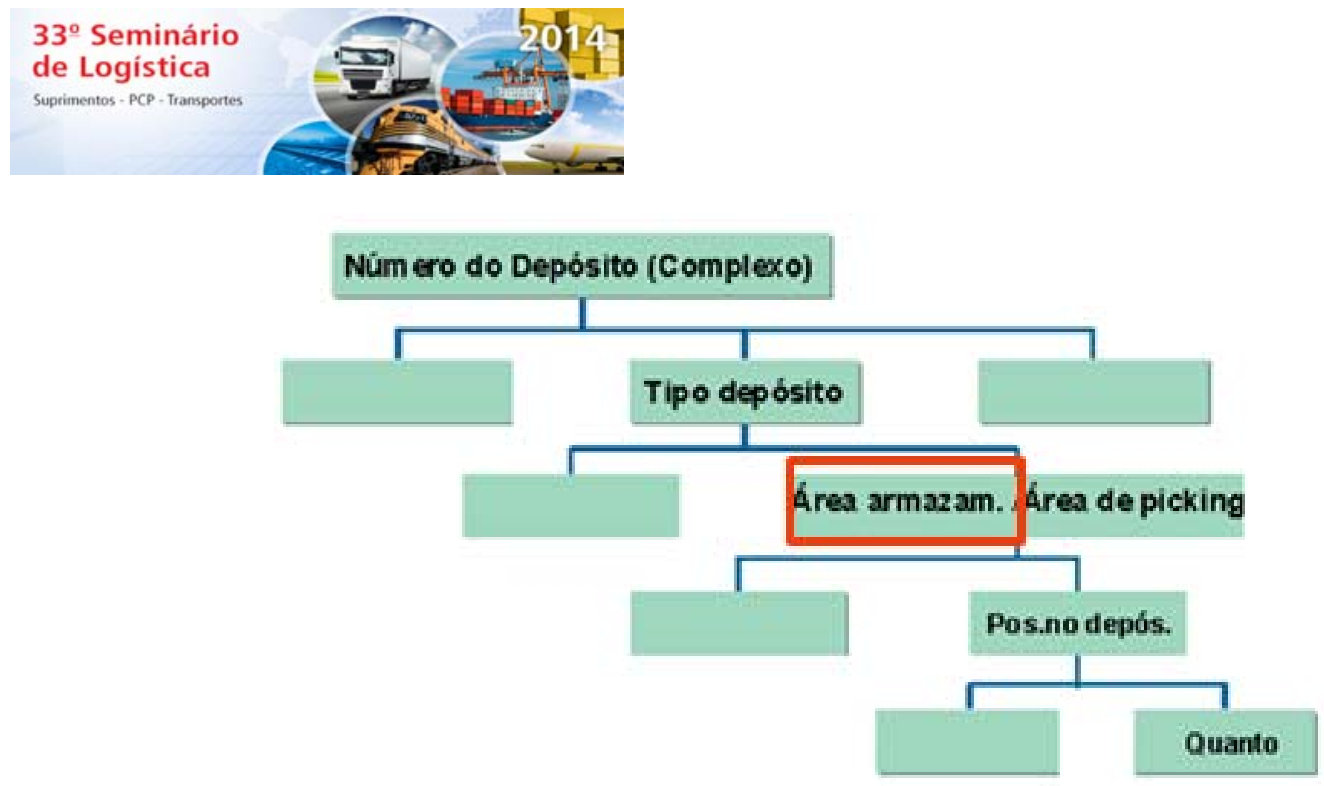

Figura 4. Representação da Estrutura do Sistema de Adm. de Depósito [4].

Desta forma atribuímos os codes de criticidade na área de armazenamento das posições constantes no cadastro mestre de posições conforme a figura 5. A definição pela utilização deste campo tem por objetivo a determinação da criticidade das áreas de estocagem, ou seja, Porta Palete de Alta, Média e Baixa criticidade de estocagem, que tem influência direta na determinação da estratégia de estocagem, movimentação dos materiais entre posições.

\begin{tabular}{|c|c|c|c|c|c|c|}
\hline $\mathbf{F}$ & Tp. & PosDepósit & CDVAZ & IA & Ár. & ÁPi \\
\hline & 001 & $\begin{array}{llll}G & 03 & 02 & 00\end{array}$ & & & PPA & G \\
\hline & 001 & $\begin{array}{llll}G & 03 & 03 & 00\end{array}$ & & & PPA & G \\
\hline L & 001 & G 03040400 & & & PPA & G \\
\hline L & 001 & G 030500 & & & PPA & G \\
\hline 다 & 001 & G 030600 & & & PPA & G \\
\hline 다 & 001 & G $03 \quad 07 \quad 00$ & & & PPA & G \\
\hline 步 & 001 & $\begin{array}{llll}G & 03 & 08 & 00\end{array}$ & & & PPA & G \\
\hline 5 & 001 & G 031100 & & & PPA & G \\
\hline L & 001 & $\begin{array}{llll}G & 03 & 12 & 00\end{array}$ & & & PPA & G \\
\hline$\square$ & 001 & $\begin{array}{lllll}G & 03 & 13 & 00\end{array}$ & & & PPA & G \\
\hline 5 & 001 & G 031400 & & & PPA & G \\
\hline L & 001 & $\begin{array}{lllll}G & 03 & 15 & 00\end{array}$ & & & PPA & G \\
\hline$\square$ & 001 & G 031600 & & & PPA & G \\
\hline 5 & 001 & G $03 \quad 17 \quad 00$ & & & PPA & G \\
\hline 든 & 001 & $\begin{array}{llll}G & 03 & 18 & 00\end{array}$ & & & PPA & G \\
\hline 5 & 001 & G 032100 & & & PPA & G \\
\hline$\square$ & 001 & G 0322200 & & & PPA & G \\
\hline
\end{tabular}

Figura 5. Modificar posições no depósito em massa [5].

Em seguida criou-se uma estratégia de entrada em depósito ( $Z^{*}$ - para uma posição no depósito que já contém estoque/próxima posição vazia da área de Aging List - Lista de Envelhecimento do material/posição $Z^{*}$ ) no $W M$, que foi utilizada para otimizar 0 armazenamento de mercadorias no almoxarifado.

A informação do Aging List dos materiais é atualizada em função do histórico de movimentação dos materiais de um determinado período de análise e gravado no

\footnotetext{
* Contribuição técnica ao $33^{\circ}$ Seminário de Logística - Suprimentos, PCP. Transportes, 13 a 16 de maio de 2014, São Paulo, SP, Brasil. 


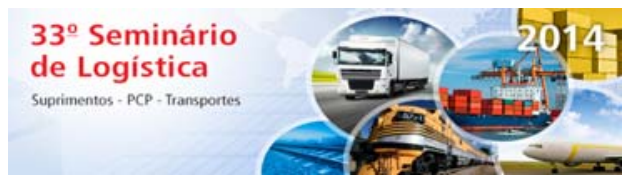

mestre de material na visão de administração de deposito - WM, conforme consta na Figura 6:

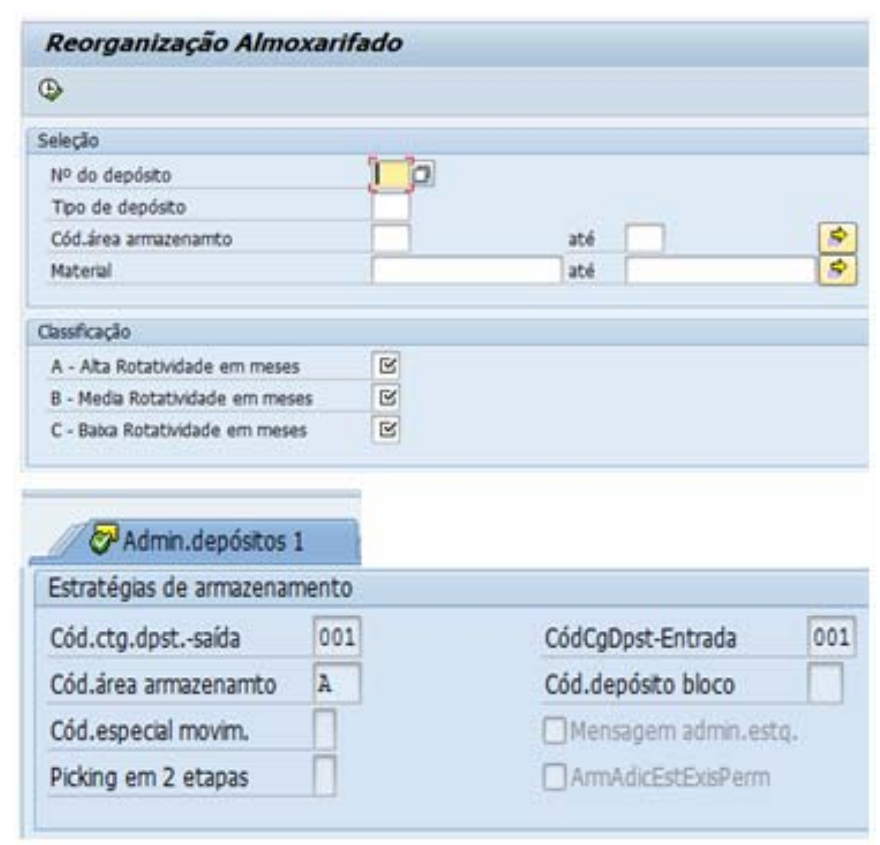

Figura 6. Execução do Aging List / Mestre de Material [6].

$\mathrm{Na}$ sequencia foi tratado o processo de Separação / Picking de Materiais onde os atendimentos de materiais no almoxarifado acontecem sempre contra uma reserva. Essas reservas podem ser para centro de custo, ordens internas e elemento PEP. Utiliza-se uma transação " $Z$ " - Plano de Retirada para gerar o agrupamento das demandas/reservas para que se inicie a separação dos materiais, etapa esta fortemente orientada e executada com a presença de fluxo de papéis, carimbos, assinaturas e arquivamento da documentação gerada.

A solução visou a automação do processo de Picking, garantindo a transferência do mapa de separação em papel para a tela do Coletor oferecendo maior agilidade e eficiência no processo baseado em uma lógica de roteirização por posição de estocagem.

O processo de Expedição/Distribuição de Materiais está ligado diretamente ao processo de Picking e também era fortemente orientada e executada com a presença de fluxo de papéis, carimbos, assinaturas e arquivamento da documentação gerada, além da evidência clara de problemas de "baixa", contabilização contábil dos materiais expedidos e entregues. A automação no processo de Distribuição o Coletor fara a leitura do item a ser entregue bem como a leitura do crachá do usuário - AMT recebedor do material (Leitura do Info Tipo de $\mathrm{RH}$ ) na modalidade de processamento "off-line", e quando do retorno ao almoxarifado o Coletor entrará no modelo "on-line" e realizará o processamento de tudo que foi armazenado garantindo a baixa, realização do movimento contábil do processamento.

\footnotetext{
* Contribuição técnica ao $33^{\circ}$ Seminário de Logística - Suprimentos, PCP, Transportes, 13 a 16 de maio de 2014, São Paulo, SP, Brasil. 


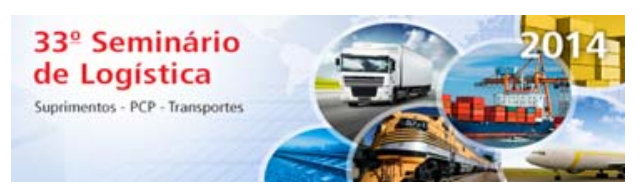

Visando a busca de excelência no processo de Gestão de Estoque a Acurácia é sinônimo de qualidade e/ou confiabilidade das informações. Na moderna gestão de estoques, a acurácia dos saldos em estoque se tornou um importante indicador gerencial que expressa, em percentagem, a proporção de informações corretas no sistema de gestão de estoques, sendo apurada através da contagem física, que é posteriormente confrontada contra o saldo contábil correspondente e desta forma a automação do processo de Inventário de Materiais parte do principio da leitura do código de barras da posição e dos materiais estocados, exigindo do usuário a entrada da contagem do material no coletor, eliminado a necessidade de papel em qualquer etapa do processo e oferecendo maior acertividade e eficiência ao processo.

Por último, mas não menos importante foi tratado o processo de Inspeção Materiais e a automação deste teve como objetivo garantir a aferição dos itens recebidos nos almoxarifados de acordo com os lotes de controle de qualidade criados no momento do registro físico dos materiais via coletor e possibilitar a transferência do material da inspeção para a área de estocagem diretamente pelo código de barras da FCQ.

Já o processo de Preservação e Materiais que visa averiguar a condição dos itens estocados, como por exemplo, se estão dentro do prazo de validade, para que medidas sejam tomadas caso o prazo esteja próximo do vencimento além de garantir o tratamento protetivo dos itens de estoque para sua utilização futura de acordo com o plano anual de preservação sendo ele realizado via decisão de utilização via coletor.

\section{CONSIDERAÇÕES FINAIS}

A opção por adotar o SAP Console como solução para aplicar recurso de Mobilidade, com Tecnologia de Códigos de Barras disponíveis no mercado e integrado com funções da plataforma ERP SAP - WM/ QM (Warehouse Management/ Quality Management) em uso na ArcelorMittal Tubarão nos processos de Movimentações e Controles dos Almoxarifados da Área de Suprimentos minimizando gargalos no gerenciamento de alocação de recursos humanos, equipamentos mecânicos e endereçamento de materiais, com a eliminação do fluxo de papéis, aumento da rastreabilidade, ganhos de agilidade de processamento e produtividade com o menor custo possível, sem perder a capacidade de reação visa preservar as práticas adotadas pela AMT de acordo com os seus padrões empresariais e garantir a eficiência de tratamento e gestão de seus processos agregando melhorias na forma de organizar os princípios podendo no tempo alcançar uma curva de aprendizado nas parametrizações alcançando níveis de detalhes de forma mais aprimorada.

\section{REFERENCIAS}

1 Banzato,E. WMS - Warehouse Management System: Sistema de gerenciamento de armazéns. São Paulo: IMAN; 1998.

2 Grizotti RR. Projeto de automatização dos almoxarifados [Power Point]. ArcelorMittal Tubarão; 2013.

3 COPPEAD. Matriz de cálculo de distância e atividade por criticidade [adaptado modelo estatístico]. Rio de Janeiro: UFRJ; 2008.

* Contribuição técnica ao $33^{\circ}$ Seminário de Logística - Suprimentos, PCP, Transportes, 13 a 16 de maio de 2014, São Paulo, SP, Brasil. 
4 SAP ECC 6.0. Knowledge Warehouse.

5 SAP ECC 6.0. Transação Módulo WM (Warehouse Management) - LS11-Modificar posições no depósito em massa.

6 SAP ECC 6.0. Transação Módulo MM (Material Management) Z* / MM03-Exibir Material.

* Contribuição técnica ao 330 Seminário de Logística - Suprimentos, PCP, Transportes, 13 a 16 de maio de 2014, São Paulo, SP, Brasil. 